\title{
Elastic linear analysis of CNC micro blanking machine using finite element method
}

\author{
Didin Zakariya Lubis ${ }^{1, *}$, Suprayitno ${ }^{1}$, Khoiruddin A. ${ }^{2}$, dan Mukhamad Andi Firismanda ${ }^{1}$ \\ ${ }^{1}$ Mechanical Engineering Department, State University of Malang, 65145 Malang, Indonesia \\ ${ }^{2}$ Electrical Engineering Department, State University of Malang, 65145 Malang, Indonesia
}

\begin{abstract}
This study has developed Micro Punch CNC Machine design by optimizing the function of the actuator axis implemented to make an implant plate. This research aimed to plan the simulation of CNC machine construction strength using the blanking operation application. Finite element method (FEM) was used to analyze the material strength. The research results showed that the maximum stress occurring at the punch tools was $428.17 \mathrm{MPa}$ with the thickness of $0.6 \mathrm{~mm}$ and the maximum thickness of workpiece allowed in making the implant plate was $1.4 \mathrm{~mm}$ with the maximum stress of $999.09 \mathrm{MPa}$. The obtained data indicate that the most effective material to be used as the material construction in CNC micro blanking machine is St42. This case is proven by the result of the power to resist the stress and the value of maximum deformation from the comparison of both materials.
\end{abstract}

\section{Introduction}

Blanking is a process of cutting by suppressing the workpiece until passing the elastic limit of the material [1]. Blanking process is used to produce thin plates since the shearing surface obtained through blanking process has high quality and high dimensional accuracy. In addition, the production process is faster [2]. Forming the material in the blanking process uses press machine to give pressure on the press dies that can cut and form the product material.

CNC (Computer Numerically Controlled) machine is a machine manufacture which can undertake material feed with many axes and various tools and operations. Some ways of workpiece feed process on the CNC machine are milling, drilling, boring, turning, shaping, planning, grinding, and blanking [3]. The previous study [4] has successfully made the first Micro Punch CNC machine prototype that can produce the bolt hole with the diameter of $500 \mu \mathrm{m}$ and $800 \mu \mathrm{m}$ on brass, copper, and titanium plates, as well as has analyzed the machine parameter to result in the best quality of cutting edge. In that study, the best clearance used $2.5 \%$ of the material thickness.

In producing certain machine, the numeric calculation or load-simulation given to the machine should be done to reduce the unexpected things and to know the limitations of loading in using the machine so that it needs longer period to use the machine [5]-[7]. Finite

* Corresponding author: didin.zakariya.ft@um.ac.id 
Element Method (FEM) is a numeric method used to finish the technical and mathematics problems of certain physical symptom [8]. [9] conducted a research using the finite element method (FEM) to simulate and predict the stress of machine tool when obtaining the high deformation. [10] utilized finite element method (FEM) to determine the number of forming steps and accuration of component geometry on Multi-Stage Incremental Forming (MSIF) operation.

This research developed Micro Punch CNC machine (first prototype) by designing and analyzing finite element on $\mathrm{CNC}$ micro blanking machine (second prototype). The construction design of CNC micro blanking machine was simulated using finite element method with the diverse choices of material and its loading to know the strength level of construction.

\section{Materials and method}

\subsection{Materials}

In this study, the analysis of static stress of CNC Micro Blanking Machine structure was undertaken using Steel St37 and Steel St42 [11], [12]. Both materials were analyzed and the efficiency of both materials was determined using a parameter of strength level and value helped by Ansys software. Table 1 presents the value of mechanical properties of Steel St37 and Steel St42 materials

Table 1. Mechanical Properties.

\begin{tabular}{|c|c|c|c|c|}
\hline Steel grade & $\begin{array}{c}\text { Tensile Strength } \\
(\mathbf{M P a})\end{array}$ & $\begin{array}{c}\text { Yield Strength } \\
(\mathbf{M P a})\end{array}$ & Poisson Ratio & $\begin{array}{c}\text { Young Modulus } \\
\text { (MPa) }\end{array}$ \\
\hline St37 & 360 & 235 & 0.3 & $205 \times 10^{3}$ \\
\hline St42 & 410 & 265 & 0.3 & $210 \times 10^{3}$ \\
\hline
\end{tabular}

\subsection{Numerical evaluation of maximum loading condition}

In this study, the data of simulation that were taken were stress, strain, and the total of deformation. The amount of loading was given based on the cutting force needed in producing keychain cranioplasty. The loading on the CNC micro blanking machine is in the reaction force of the cutting force in producing keychain cranioplasty. The cutting force of this machine is symbolized by the letter of "P" formulated as follow.

$$
\mathrm{P}=\alpha \times \sigma_{\mathrm{t}} \times \mathrm{s} \times \mathrm{K}
$$

The correction factor with the value of 0.8 is symbolized with " $\alpha$ ", the tensile strength of the material is symbolized with " $\sigma_{t}$ ", the thickness of the material is symbolized with " $s$ ", and the circumference of the material is symbolized with " $\mathrm{K}$ ". The circumference adjusts the form of keychain cranioplasty formulated as follow.

$$
\mathrm{K}=(2 \times \text { length })+(2 \times[\text { Kcircle }- \text { Koval }])
$$

The following table 2 presents the variations of loading in the simulation process for St37 and St42 materials. The design of CNC micro blanking machine was given a big load passing the maximum limit of the machine construction. This case is to know the loading limit allowed by the machine that would be produced. The maximum loading is varied by the thickness of the keychain cranioplasty: $0.6,1.0,1.2,1.4$, and $1.6 \mathrm{~mm}$. Meanwhile, the type of pedestal used in this CNC micro blanking machine is the fixed support on the machine basis. 
Table 2. Various punching process loading for Titanium 6Al-4V Material in the application of Keychain Cranioplasty.

\begin{tabular}{|c|c|c|c|c|}
\hline Steel grade & $\begin{array}{c}\text { Tensile Stress }\left[\sigma_{t}\right] \\
\text { (MPa) }\end{array}$ & $\begin{array}{l}\text { Thickness [s] } \\
\text { (mm) }\end{array}$ & $\begin{array}{c}\text { Circumference } \\
{[\mathrm{K}](\mathbf{m m})}\end{array}$ & $\begin{array}{l}\text { Shearing Force }[\mathbf{F}] \\
(\mathbf{N})\end{array}$ \\
\hline \multirow{5}{*}{ St37, St42 } & \multirow{5}{*}{860} & 0.6 & \multirow{5}{*}{29.94} & 12360.7 \\
\hline & & 1.0 & & 20601.1 \\
\hline & & 1.2 & & 24721.4 \\
\hline & & 1.4 & & 28841.6 \\
\hline & & 1.6 & & 32961.8 \\
\hline
\end{tabular}

\subsection{Modeling of cnc micro blanking machine}

On the CNC micro blanking machine, the actuator axis is functioned to move the workpiece so that the time of production is briefer and the rest of materials can be minimized since the movement of the workpiece is controlled and taken into account using G code. It is different from the first prototype machine where its actuator axis is functioned for the alignment process between the punch and die. The Figure 1 is the design of CNC Micro blanking machine.

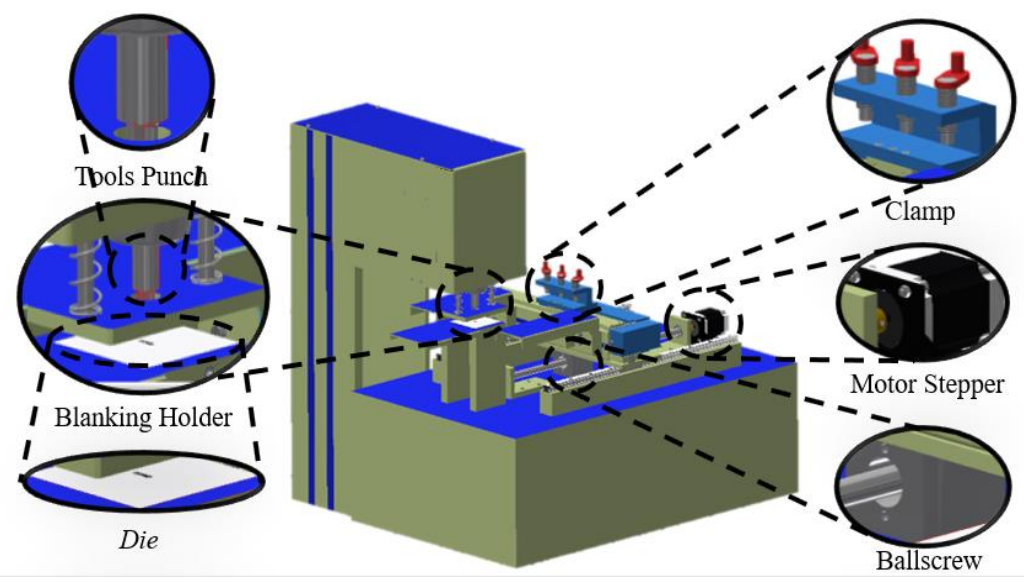

Fig. 1. Design of CNC Micro Blanking machine.

The production of CNC micro blanking machine will be implemented in making the implant plate in the form of keychain cranioplasty plate and the maximum load to know the failure of the construction. An implant plate is a medical tool made to change the structure and function of human's certain biological part (fixation) [13]. The implant plate that is available until now is still obtained by importing from abroad, especially Europe [14]. Meanwhile, the structure of the Indonesian human's bone is relatively smaller than the Europeans'. The use of too big size-plate causes the overloaded bone, the obstruction of blood circulation in the bones, even the instability of the plate when it is attached in the bones [15]. Such phenomena support the production of CNC micro blanking machine to make the implant plate in accordance with Indonesian people's bone structure.

Before performing simulation, the meshing process was carried out, the type of pedestal and the amount of load used in CNC micro blanking machine were determined. Figure 2 presents the meshing view in the CNC Micro blanking machine design. 


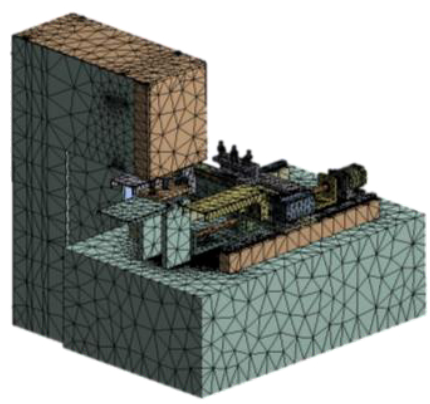

Fig. 2. Meshing view of CNC Micro blanking machine.

\section{Results and Discussion}

\subsection{Simulation Results}

The analysis of Finite element model of CNC micro blanking machine was accomplished by Ansys FEA presented in Table 2. In this research, the results of the simulation discussed are from the aspect of stress, strain, and the total of deformation. From such aspects, the $\mathrm{CNC}$ micro blanking machine design is viewed whether it is feasible to be used and it also determines the allowed maximum loading.
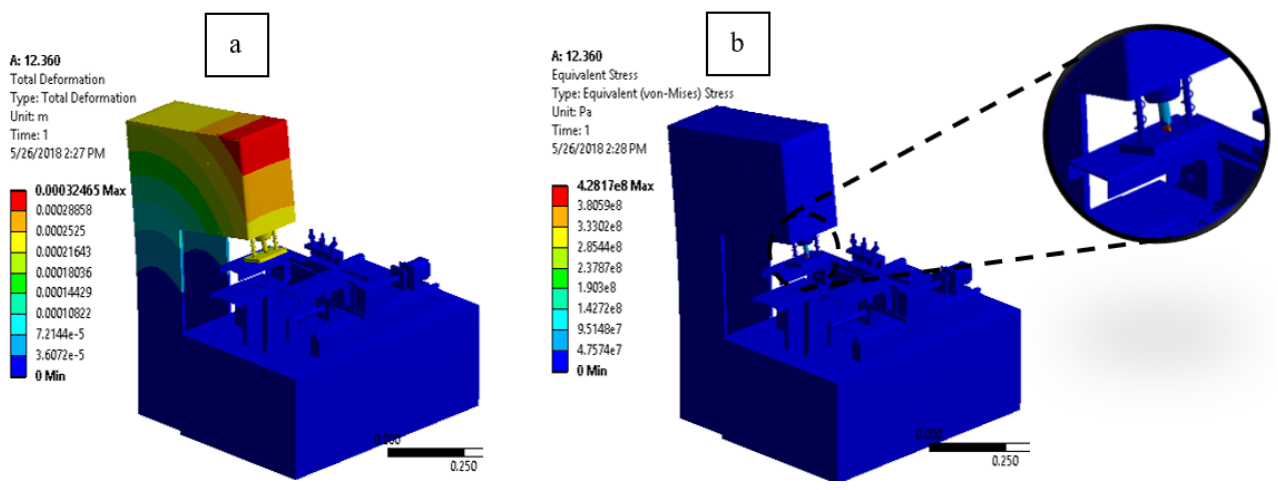

Fig. 3. (a) The total of deformation and (b) Stress of the St37 Material.

Figure 3 (a) shows that the deformation analysis of St37 material exhibits that the simulation results on all structures showed blue color with the value less than $0.003 \mathrm{~mm}$, while the total of maximum deformation was $0.324 \mathrm{~mm}$ located on the motor stepper of the $\mathrm{Z}$ axis. Meanwhile, in figure 3 (b), holistically, the design of machine structure is shown by blue color. The maximum stress was $428.17 \mathrm{MPa}$ on the punch tools. This component was made of HSS material with the yeild strength of $1034 \mathrm{MPa}$. Based on such data, it is proven that the structure of CNC micro blanking machine model is safely useable. 

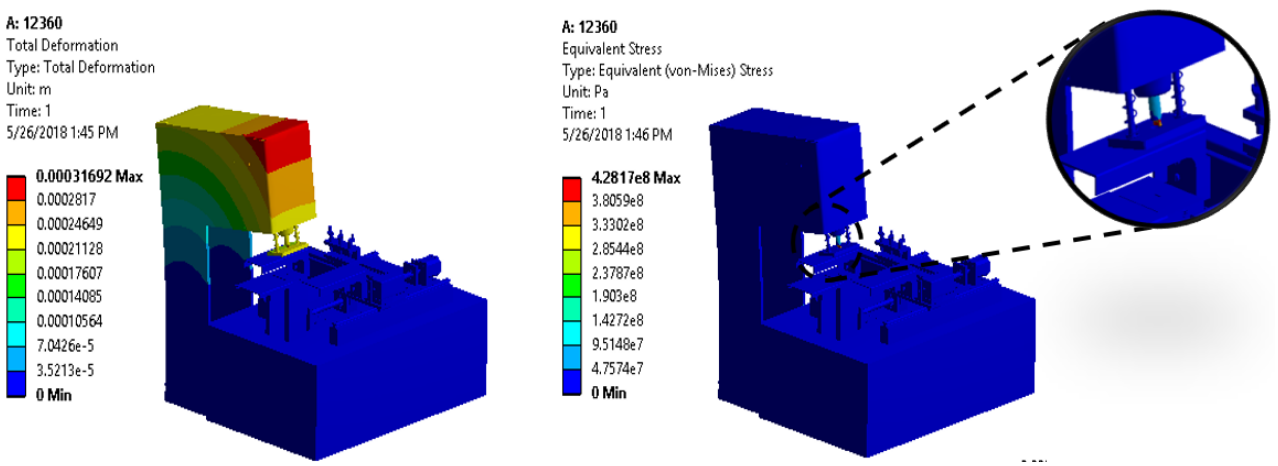

Fig. 4. (a) The total of deformation and (b) Stress of the St42 Material.

The total of deformation and maximum stress in figure 4 can be seen in Table 3 . The table shows that the values of stress, strain, and the total of deformation were not significantly different.

Table 3. The Simulation Results of St 37 and St 42

\begin{tabular}{|c|c|c|c|c|c|}
\hline No & Material & $\begin{array}{c}\text { Thickness } \\
(\mathbf{m m})\end{array}$ & $\begin{array}{c}\text { Stress } \\
\mathbf{( M P a )}\end{array}$ & $\begin{array}{c}\text { Strain } \\
(\mathbf{m m})\end{array}$ & $\begin{array}{c}\text { Total of } \\
\text { Deformation } \\
(\mathbf{m m})\end{array}$ \\
\hline 1. & St37 & 0.6 & 428.17 & 2.116 & 0.324 \\
\hline 2. & St42 & 0.6 & 428.17 & 2.065 & 0.316 \\
\hline
\end{tabular}

\subsection{Load Comparison and Material Discussion}

The simulation results of stress in St37 and St42 materials had the similar value namely 428.17 MPa. The simulation results of strain and the total of deformation in St42 had better strength but the resulted values were not far different from St37. The difference of the total of deformation was $0.0077 \mathrm{~mm}$ and that of strain was $0.0504 \mathrm{~mm}$. Therefore, the strength level of the materials could be similar. If the values of both materials are compared, the St37 material is more effective to be used. In addition, the level of availability should be considered as well.

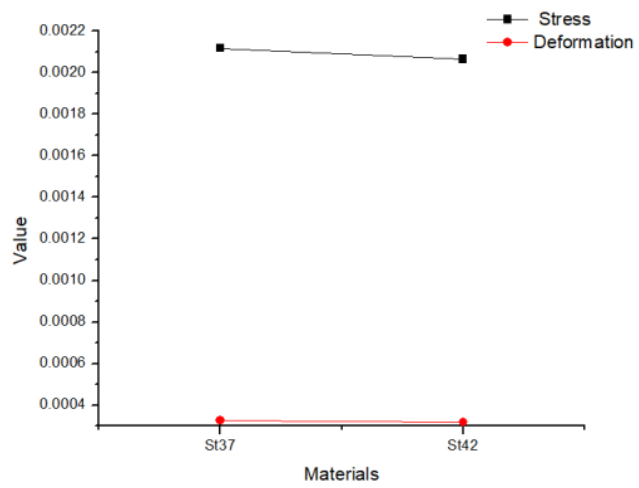

Fig. 5. Diagram of simulation results of St37 and St42.

The loading on CNC micro blanking machine is a reaction force of cutting force in producing keychain cranioplasty. Hence, in determining the maximum limit of loading 
allowed is by using the various thicknesses of keychain cranioplasty. The maximum stress, in this case, happened in the part of the punch tool namely part SKD11. This component was made of HSS material with the yield strength of $1034 \mathrm{MPa}$. Therefore, the allowed stress limit is not more than $1034 \mathrm{MPa}$.

Table 4. Simulation result comparison.

\begin{tabular}{|c|c|c|c|c|c|}
\hline No & Material & $\begin{array}{l}\text { Thickness } \\
\text { (mm) }\end{array}$ & Stress (MPa) & $\begin{array}{c}\text { Strain } \\
(\mathrm{mm})\end{array}$ & $\begin{array}{c}\text { Total of } \\
\text { Deformation }(\mathrm{mm})\end{array}$ \\
\hline 1. & \multirow{5}{*}{ St37 } & 0.6 & 428.17 & 2.1160 & 0.3246 \\
\hline 2. & & 1.0 & 713.65 & 3.5268 & 0.5411 \\
\hline 3. & & 1.2 & 856.37 & 4.2321 & 0.6493 \\
\hline 4. & & 1.4 & 999.09 & 4.9374 & 0.7575 \\
\hline 5. & & 1.6 & 1141.8 & 5.6428 & 0.8657 \\
\hline 6. & \multirow{5}{*}{ St42 } & 0.6 & 428.17 & 2.0656 & 0.3169 \\
\hline 7. & & 1.0 & 713.65 & 3.4428 & 0.5282 \\
\hline 8. & & 1.2 & 856.37 & 4.1313 & 0.6338 \\
\hline 9. & & 1.4 & 999.09 & 4.8199 & 0.7395 \\
\hline 10. & & 1.6 & 1141.80 & 5.5084 & 0.8451 \\
\hline
\end{tabular}

Table 4 shows that the simulation results present the similar value of stress between St37 and St42 materials. The maximum thickness that could be accommodated by a punch tip tool available in the production of keychain cranioplasty was $1.4 \mathrm{~mm}$ with the strain value of $999.09 \mathrm{MPa}$.

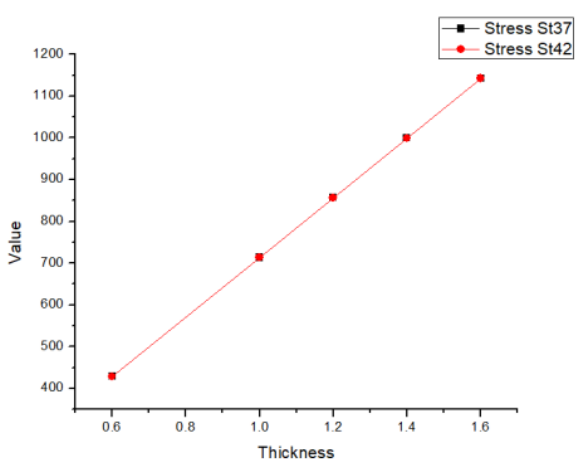

(a)

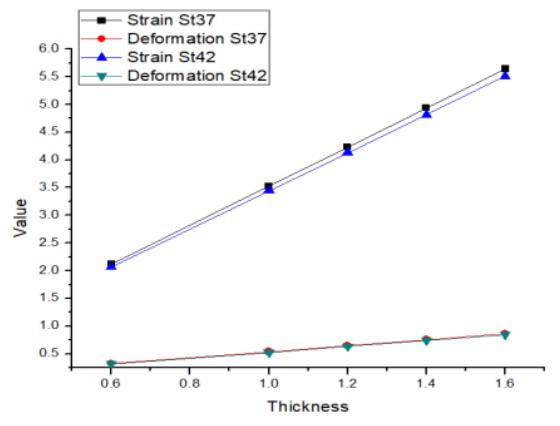

(b)

Fig. 6. (a) The Result diagram of Stress of St37 and St42, (b) The result diagram of Strain and Deformation of St37 and St42.

These research results shown at Figure 6 are in line with the results of finite element simulations undertaken by [5], [6] showing that the highest stress occurred on the surface or the part that is directly intersected with its force. Hence, the failure possibly happens with the lower force if the material tool does not employ the standard material tool commonly used. Besides, the principal factor determining the destruction of the construction and tool is when the dynamic load occurs caused by the vibration and punching process.

\section{Conclusion}

The results of the modulus elasticity of the data averagely reached $202 \mathrm{MPa}$ while the maximum elasticity modulus of St37 and St42 was $210 \times 10^{3} \mathrm{MPa}$. It can be analyzed that the deformation occurring in $\mathrm{CNC}$ micro blanking machine, in the blanking process, is still 
in the safe range. Seeing the data attained between St37 and St42 materials, St37 is the most effective material to be used as the construction material in CNC micro blanking machine. This case is viewed from the aspect of the result of the strength in resisting the stress and the maximum deformation from the comparison of both materials which are not significant. The further research is recommended to conduct FEA analysis on the dynamic load.

The authors gratefully acknowledge the support of Universitas Negeri Malang, Malang, Indonesia, for the PNBP Research Program issued on the letter number 21.2.6/UN32.14/LT/2018.

\section{References}

1. T. Altan, A.E. ekkaya. ASM International. 2-3. (2012)

2. S. Jana and N. S. Ong, J. Mech. Work. Technol.,19, pp. 55-72, (1989)

3. M. Deng, Y. Ma, and L. Lv, Procedia Eng., 81, pp. 1157-1162, (2014)

4. D.Z. Lubis and M. Muslim, IOP Conf. Ser.: Mater. Sci. Eng. 157, (2016)

5. C. C. Hong, C. L. Chang, and C. Y. Lin, Eng. Sci. Technol. an Int. J., 19, no. 4, pp. 1971-1984, (2016)

6. H. Yang, R. Zhao, W. Li, C. Yang, and L. Zhen, Procedia Eng., 174, pp. 489-496, (2017)

7. A. Afkhamifar, D. Antonelli, and P. Chiabert, Procedia CIRP, 43, pp. 118-123, (2016)

8. S. Moaveni, Library of Congres Cataloging, (1999)

9. M. Zaeh and D. Siedl, CIRP Ann. Manuf. Technol., 56 pp. 383-386, (2007)

10. K. Suresha, S. P. Regallaa, N. Kotkundae, Materials Today: Proceedings, 5 38023810, (2018)

11. Y. Shneor, Procedia Manuf., 21, no. 2017, pp. 221-227, (2018)

12. A. N. M. Amanullah, T. Saleh, and R. Khan, Procedia Eng., 184, pp. 163-170, (2017)

13. S. Duffett, I. El Hajjaji, J. Manlucu, and R. Yee, Card. Electrophysiol. Clin., 10, no. 1, pp. 119-125, (2018)

14. B. Wongchai, J. Comput. Sci., 7, no. 4, pp. 466-470, (2011)

15. C. K. Lee, M. K. Kwan, M. S. Ortho, Y. P. Chua, and M. S. Ortho, A Report of Three Cases, 3, no. 1, pp. 85-87, (2009) 